\title{
El Estado de derecho como valor fundamental de la unión europea'
}

The rule of law as a fundamental value of the european unión

Alvaro A. Sánchez Bravo²

Recibido: 17/09/2020 - Aprobado: 02/11/2020 - Publicado: 30/11/2020

\section{Resumen:}

El Estado de Derecho constituye un elemento imprescindible para una democracia plena. No obstante, su acogida como valor fundamental en los Tratados y la legislación de la Unión Europea, se están produciendo fuertes ataques al mismo, que están intentando ser sofocados con los mecanismos institucionales adecuados, con dispar éxito, lo que lleva a la necesidad de replantear con más contundencia esta cuestión en el seno de la organización comunitaria europea.

Palabras Clave: Estado, Derecho, Democracia, Europa

\section{Abstract:}

The rule of law is an essential element for a full democracy. However, its reception as a fundamental value in the Treaties and the legislation of the European Union, strong attacks are taking place on it, which are trying to be quelled with the appropriate institutional mechanisms, with mixed success, which leads to the need to rethink with more forcefulness this question within the European community organization.

Keywords: State, Law, Democracy, Europe.

\footnotetext{
1 Texto revisado, ampliado y actualizado de mi artículo "Reforzar el Estado de Derecho en la Unión Europea" en la obra colectiva, edic., a cargo de A. Sánchez Bravo, Derechos Humanos, Ciudadanía y Globalización, Punto Rojo Libros, Sevilla, 2017, pp. 170-186.

2 Doctor en Derecho. Universidad de Sevilla. Facultad de Derecho. Sevilla. España. elialva@us.es. ORCID: 00000002-8610-3240
} 


\section{Introducción}

En un Estado de Derecho, todos los poderes públicos actúan siempre dentro de los límites fijados por la ley, de conformidad con los valores de la democracia y los derechos fundamentales, y bajo el control de órganos jurisdiccionales independientes e imparciales (Comité Económico y Social Europeo [CESE], 2019, p.1)

Conforme al art. 2 del Tratado de la Unión Europea,

La Unión se fundamenta en los valores de respeto de la dignidad humana, libertad, democracia, igualdad, Estado de Derecho y respeto de los derechos humanos, incluidos los derechos de las personas pertenecientes a minorías. Estos valores son comunes a los Estados miembros en una sociedad caracterizada por el pluralismo, la no discriminación, la tolerancia, la justicia, la solidaridad y la igualdad entre mujeres y hombres (Unión Europea [UE], 2010, p.20) ${ }^{3}$

No obstante, estos importantes valores, han acontecido en algunos Estados miembros (por ejemplo, los casos de Polonia (UE, 2016) ${ }^{4}$ y Hungría (UE, 2016) los cuales $^{5}$ han demostrado la falta de respeto a los mismos, y como la Unión Europea carece de mecanismos adecuados para responder rápidamente a las amenazas a que pueda estar sometida la democracia de un Estado miembro frente al irrespeto o no consolidación de dichos valores dentro de los Estados que los infunden.

A pesar de lo anterior, el respeto a la democracia y los valores en que se fundamenta constituye, a nivel europeo, el soporte de la confianza entre los Estados y el basamento de la garantía de los derechos fundamentales de los ciudadanos. Los derechos humanos y la democracia se refuerzan mutuamente. Si bien, los sistemas democráticos pueden manifestarse de diferentes formas, todos ellos tienen el común denominador de lograr el respeto de los derechos humanos, ya sean civiles y políticos o económicos, sociales y culturales. (UE, 2016, p.34)

Además, como ha señalado el CESE, "la Unión Europea no es sólo un mercado común; es una unión de valores comunes...Estos valores, en los que se basa la Unión Europea, constituyen el fundamento de la integración y forman parte de la integridad europea”. (CESE, 2016)

Pero de mano a la democracia y los derechos humanos, el Estado de Derecho constituye uno de los tres pilares de la arquitectura axiológica de la Unión, constituyendo la columna vertebral de las democracias constitucionales modernas, que derivan de las tradiciones constitucionales comunes a todos los Estados miembros de la Unión (Comisión Europea [CE], 2014, p.2)

\footnotetext{
Igualmente, conforme al art, 49 TUE, el respeto del Estado de Derecho es un requisito para imprescindible para la adhesión a la UE.

Recomendación (UE) 2016/1374 de la Comisión, de 27 de julio de 2016, relativa al Estado de Derecho en Polonia. sobre el Estado de Derecho en Polonia que complementa la Recomendación (UE) 2016/1374
} 
Ahora bien, el contenido concreto de los principios y normas que se derivan del Estado de Derecho pueden manifestarse de manera diferente en cada Estado miembro. Inicialmente, los sistemas constitucionales y la estructura del poder judicial de los diferentes Estados Miembros UE, están teóricamente establecidos y dotados de mecanismos para proteger a los ciudadanos de las amenazas que sobrevuele el Estado de Derecho, pero, en la realidad, se ha demostrado que la violación del Estado de Derecho, y demás valores democráticos, puede convertirse en un grave problema .En los casos en que la Unión ha tenido que hacer frente a estas situaciones, no en todos los casos se ha conseguido articular una respuesta eficaz y rápida frente a las amenazas que se han presentado. (CE, 2014, p.2)

\section{El Estado de Derecho en la unión europea}

Señala Pérez Luño (2003), como:

La idea guía del Estado de Derecho, en el que los derechos fundamentales no aparecen como concesiones, sino como el corolario de la soberanía popular, a través de cuyo principio la ley no sólo implica un deber, sino también un derecho para el individuo. Se cumplía así el axioma a tenor del cual el hombre sólo puede ser libreen un Estado libre, y el Estado sólo es libre cuando se edifica sobre un conjunto de hombres libres. (p.212)

Estas esclarecedoras palabras nos indican también como dentro de la UE, y dada su arquitectura organizativa, el Estado de Derecho, reviste una importancia capital, constituyendo un elemento necesario para defender los derechos y las diferentes obligaciones que surgen a partir de la constatación de los Tratados y del Derecho Internacional. Como ha señalado la Comisión, la confianza por parte de los ciudadanos y de las autoridades nacionales al derecho internacional es totalmente trascendental para que pueda funcionar la UE "como un espacio de libertad, seguridad y justicia sin fronteras interiores". (CE, 2014, p.5)

Además, no debe olvidarse que estamos hablando de derechos de las personas, no de los gobiernos ni de los Estados Miembros, por lo que la prioridad en su defensa debe ser inmediata (CESE, 2016).

Con anterioridad a que el principio del Estado de Derecho se mencionara explícitamente en los Tratados, fue el Tribunal de Justicia, en su jurisprudencia, el que ha determinado como el Estado de Derecho es la fuente de principios plenamente justiciables aplicables en el ordenamiento jurídico de la UE. (CESE, 2014, p.1)

Siguiendo lo establecido por la propia Comisión Europea, y transcribiendo su propia iniciativa, indicar que los principios que pueden incardinarse dentro del Estado de Derecho son los siguientes: 
a) El principio de legalidad, que en términos sustanciales implica la existencia de un proceso legislativo transparente, responsable, pluralista y democrático. El Tribunal de Justicia ha confirmado el principio de legalidad como un principio fundamental de la Unión, al afirmar que «[...] en una comunidad de Derecho, debe garantizarse debidamente el respeto de la legalidad» (Tribunal de Justicia de la Unión Europea, 2004, párr,64)

b) La seguridad jurídica, que requiere, entre otras cosas, que las normas sean claras y previsibles y no puedan modificarse retroactivamente. El Tribunal de Justicia ha puesto de relieve la importancia de la seguridad jurídica al afirmar que, en virtud de los principios de seguridad jurídica y de protección de la confianza legítima, «[...] los efectos de la legislación de la [Unión] deben ser claros y previsibles para quienes están sujetos a ella [...]». El Tribunal declaró también que «[...] el principio de seguridad jurídica se opone a que un acto [de la Unión] entre en vigor antes de su publicación, y que solo podría ser de otro modo, con carácter excepcional, cuando la finalidad que debe conseguirse lo exija y cuando se respeten debidamente las expectativas legítimas de los afectados» (Tribunal de Justicia de la Unión Europea, 1981)

c) Prohibición de arbitrariedad de los poderes ejecutivos. El Tribunal de Justicia ha declarado lo siguiente: «Sin embargo, en todos los sistemas jurídicos de los Estados miembros las intervenciones de los poderes públicos en la esfera de actividad privada de cualquier persona, sea física o jurídica, han de tener un fundamento legal y estar 1 La primera referencia al Estado de Derecho figura en el preámbulo del Tratado de Maastricht de 1992. El Tratado de Ámsterdam hace referencia al Estado de Derecho en el artículo 6, apartado 1, en términos sustancialmente idénticos a los del actual artículo 2 del TUE. 2 Asunto 294/83, «Les Verts» contra Parlamento Europeo, Rec. 1986, 01339, apartado 23. 3 Asunto C-496/99 P, Comisión contra CAS Succhi di Frutta Rec. 2004, I-03801, apartado 63. 4 Asuntos acumulados 212 a 217/80 Amministrazione delle finanze dello Stato contra Salumi, Rec. 2735, apartado 10. 1 justificadas por las causas previstas en la Ley, y, en consecuencia, dichos sistemas prevén, con diferentes modalidades, una protección frente a las intervenciones que fueren arbitrarias o desproporcionadas. La exigencia de esta protección debe, por tanto, ser reconocida como un principio general del Derecho [de la Unión] [...]» (Tribunal de Justicia Europea, 1989, párr, 19)

d) Tutela judicial efectiva e independiente, incluido el respeto de los derechos fundamentales. El Tribunal reiteró que «la Unión es una Unión de Derecho cuyas instituciones están sujetas al control de la conformidad de sus actos, en particular, con los Tratados, con los principios generales del Derecho y con los derechos fundamentales». El Tribunal especificó que esto supone, en particular, que «los particulares deben poder disfrutar de una tutela judicial efectiva de los derechos que les confiere el ordenamiento jurídico [de la Unión]». El Tribunal ha precisado claramente que el derecho a dicha tutela «forma parte de los principios generales del Derecho que resultan de las tradiciones constitucionales comunes a los Estados miembros. Este derecho también ha sido consagrado en los artículos 6 y 13 del Convenio Europeo de Derechos Humanos» (Tribunal de Justicia de la Unión Europea, 2013, párr,91).

e) Además, por lo que respecta a la relación entre el derecho a un juicio justo y la separación de poderes, el Tribunal declaró expresamente que «[...] el principio general del Derecho [de la Unión] según el cual toda persona tiene derecho a un juicio justo, principio que se inspira en el artículo 6 del CEDH [...] implica el derecho a un tribunal independiente, en particular del poder ejecutivo [...]»7 . El principio de la separación de poderes, desde luego, es un elemento importante para garantizar el respeto del principio del Estado de Derecho. No obstante, 
puede adoptar diferentes formas, dados los distintos modelos parlamentarios y los diferentes grados en que este principio se aplica en el ámbito nacional. A este respecto, el Tribunal de Justicia se refería a la separación operativa de los poderes, que implica una tutela judicial independiente y efectiva, señalando que «[...] el Derecho de la Unión no se opone a que un Estado miembro reúna las funciones de legislador, administrador y juez, siempre que estas se ejerzan respetando el principio de separación de poderes propio del funcionamiento de un Estado de Derecho» (Tribunal de Justicia de la Unión Europea, 2010, párr,58)

f) Igualdad ante la ley. El Tribunal ha destacado el papel de la igualdad de trato como principio general del Derecho de la UE, señalando que «procede recordar que el principio de igualdad de trato constituye un principio general del Derecho de la Unión, consagrado por los artículos 20 y 21 de la Carta de los Derechos Fundamentales de la Unión Europea» (Tribunal de Justicia de la Unión Europea, 2010, párr,54).

La labor jurisprudencial desarrollada por el Tribunal de Justicia de la Unión Europea, confirma como estos principios no son requisitos meramente formales y procedimentales, o hasta cosméticos, como pretenden algunos y algunos Estados, sino que son el instrumento canalizador que garantiza el respeto y cumplimiento de los derechos fundamentales y de la democracia.

\section{Necesidad de proteger y reforzar el Estado de Derecho: mecanismos sancionadores en la unión europea}

La erosión del Estado de Derecho, la gobernanza democrática y los derechos fundamentales constituye una grave amenaza para la seguridad, estabilidad y prosperidad de la Unión. Como señala el Parlamento Europeo,

La definición de los valores y principios fundamentales es un proceso permanente y dinámi$c o$, y que, si bien dichos valores y principios pueden evolucionar con el tiempo, deben protegerse frente al cortoplacismo y los cambios ad hoc resultantes de la sucesión de diferentes mayorías políticas. (Parlamento Europeo, 2016, p.5)

Como indicamos anteriormente la Unión Europea no se encuentra en su mejor momento. Fenómenos de diversa etiología e intensidad contribuyen a esta situación. Por un lado, un deficiente sistema institucional y normativo que carece de contundencia para resolver estas cuestiones, o que como veremos posteriormente, solo actúa en casos de violación "persistente y grave". A nivel de los Estados miembros, algunas democracias han girado, bien desde sus gobiernos, bien desde sus parlamentos, hacia posiciones extremas, de corte nacionalista y autoritarias, comprometiendo gravemente el respeto de los derechos fundamentales en sus territorios. Por otro lado, la Unión europea vive una crisis humanitaria (Sánchez, 2017), que no de refugiados, que cuestiona nuestro sistema democrático y los valores que fundamentan la Unión, y que genera graves disensiones entre los Estados miembros, e incluso, con algunas organizaciones internacionales. 
Todo esto ha puesto a prueba los valores y la solidaridad de la Unión. Frente a estos desafíos, es esencial salvaguardar los valores comunes de la democracia, los derechos fundamentales y el Estado de Derecho (Comisión Europea, 2016, p.2)

La Unión Europea dispone de mecanismos, uno general, y otro particular, para actuar ante situaciones de incumplimiento grave y reiterado.

El procedimiento general, procedimiento de infracción, se regula en el art.258 del Tratado de Funcionamiento de la Unión Europea ${ }^{6}$, que otorga a la Comisión Europea las competencias de control de la aplicación del Derecho de la Unión, velando por su buena aplicación y por la de las decisiones tomadas para este fin.

El procedimiento de infracción puede ser iniciado por la Comisión Europea de oficio o como consecuencia de una denuncia o queja de cualquier persona física o jurídica.

Por regla general, previamente al inicio de un expediente de infracción, la Comisión recurre a un diálogo estructurado -piloto UE- que facilita la comunicación y la resolución de problemas de aplicación del Derecho de la UE entre los servicios de la Comisión y las autoridades de los Estados miembros. Concluido sin éxito este procedimiento en fase temprana o en los casos en que no recurra al mismo, se pasa a la primera fase o fase administrativa del procedimiento de infracción en la que la Comisión solicita al Estado miembro, mediante una carta de emplazamiento, que le comunique en un determinado plazo sus observaciones sobre un determinado problema de aplicación del Derecho comunitario. Si no hay respuesta o la respuesta no es satisfactoria, elabora un dictamen motivado, en el que se pronuncia sobre la infracción y fija el contenido de un posible recurso por incumplimiento e insta al Estado a que se ponga fin al mismo en el plazo establecido.

Si el Estado miembro no pusiere fin al incumplimiento en el plazo señalado, la Comisión puede acudir al Tribunal de Justicia, iniciándose así la fase contenciosa del procedimiento de infracción, solicitando una sentencia que se pronuncie sobre el incumplimiento. Si, tras la sentencia, la Comisión considera que el Estado afectado no ha tomado las medidas necesarias para ejecutarla, pone en marcha el procedimiento previsto en el artículo 260 del TFUE, y recurre por segunda vez al Tribunal de Justicia, después de haberle dado a aquél la oportunidad de presentar sus alegaciones, proponiendo, esta vez, la imposición de una multa que puede ser una cantidad a tanto alzado, como sanción por el incumplimiento en sí, y/o una multa coercitiva que se devenga diariamente mientras no se cumpla la sentencia.

La posibilidad de imponer sanciones económicas al Estado miembro que no haya ejecutado una sentencia por incumplimiento fue introducida por el Tratado de Maastricht que modificó a tal efecto el artículo 171 del Tratado CEE, actualmente el artículo

\footnotetext{
${ }^{6}$ Si la Comisión estimare que un Estado miembro ha incumplido una de las obligaciones que le incumben en virtud de los Tratados, emitirá un dictamen motivado al respecto, después de haber ofrecido a dicho Estado la posibilidad de presentar sus observaciones.

Si el Estado de que se trate no se atuviere a este dictamen en el plazo determinado por la Comisión, ésta podrá recurrir al Tribunal de Justicia de la Unión Europea.
} 
260, apartados 1 y 2, del TFUE. La Comisión adoptó, el 13 de diciembre de 2005, una Comunicación en la que establece la base sobre la que se calcula el importe de las sanciones (suma a tanto alzado o multa coercitiva).

Por su parte, el procedimiento especial, quedó establecido para aquellos supuestos en que se producen situaciones problemáticas no vinculadas a la aplicación de la legislación europea, y por tanto no computables como inobservancia de las obligaciones impuestas en los Tratados, pero que suponen una amenaza para el Estado de Derecho.

El art. 7 TUE (Tratado de Maastricht, 1992) ${ }^{7}$, tiene por objeto garantizar que todos los países que hacen parte de la UE respeten los valores comunes de la Unión, incluido el Estado de Derecho. Su ámbito de aplicación no se limita a las áreas cubiertas por legislación de la Unión Europea, sino que permite la intervención para proteger el Estado de Derecho cuando los Estados miembros actúen de manera autónoma conforme a sus legislaciones interna. Como explica la propia Comisión,

El carácter horizontal y general del posible ámbito de aplicación del artículo 7 TUE se entiende fácilmente por cuanto se refiere a un artículo cuyo objetivo es garantizar que se respetan las condiciones de pertenencia a la Unión. En efecto, sería paradójico limitar las posibilidades de intervención de la Unión exclusivamente al ámbito de aplicación del Derecho de la Unión y permitir a ésta ignorar las violaciones graves que pudieran producirse en los ámbitos de competencia nacional. En efecto, que un Estado miembro vulnere los valores fundamentales con un grado de gravedad tal que alcance la requerida para la aplicación del artículo 7 pudiera minar las bases mismas de la Unión y de la confianza entre sus miembros, fuere cual fuese el ámbito en el que se produjeren las violaciones.

\footnotetext{
7 1. A propuesta motivada de un tercio de los Estados miembros, del Parlamento Europeo o de la Comisión, el Consejo, por mayoría de cuatro quintos de sus miembros y previa aprobación del Parlamento Europeo, podrá constatar la existencia de un riesgo claro de violación grave por parte de un Estado miembro de los valores contemplados en el artículo 2. Antes de proceder a esta constatación, el Consejo oirá al Estado miembro de que se trate y por el mismo procedimiento podrá dirigirle recomendaciones. El Consejo comprobará de manera periódica si los motivos que han llevado a tal constatación siguen siendo válidos.

2. El Consejo Europeo, por unanimidad y a propuesta de un tercio de los Estados miembros o de la Comisión y previa aprobación del Parlamento Europeo, podrá constatar la existencia de una violación grave y persistente por parte de un Estado miembro de los valores contemplados en el artículo 2 tras invitar al Estado miembro de que se trate a que presente sus observaciones.

3. Cuando se haya efectuado la constatación contemplada en el apartado 2, el Consejo podrá decidir, por mayoría cualificada, que se suspendan determinados derechos derivados de la aplicación de los Tratados al Estado miembro de que se trate, incluidos los derechos de voto del representante del Gobierno de dicho Estado miembro en el Consejo. Al proceder a dicha suspensión, el Consejo tendrá en cuenta las posibles consecuencias de la misma para los derechos y obligaciones de las personas físicas y jurídicas. 30.3.2010 Diario Oficial de la Unión Europea C 83/19 ES Las obligaciones del Estado miembro de que se trate derivadas de los Tratados continuarán, en cualquier caso, siendo vinculantes para dicho Estado.

4. El Consejo podrá decidir posteriormente, por mayoría cualificada, la modificación o revocación de las medidas adoptadas de conformidad con el apartado 3 como respuesta a cambios en la situación que motivó su imposición.

5. Las modalidades de voto que, a los efectos del presente artículo, serán de aplicación para el Parlamento Europeo, el Consejo Europeo y el Consejo se establecen en el artículo 354 del Tratado de Funcionamiento de la Unión Europea.
} 
El artículo 7 otorga pues a la Unión una competencia de intervención muy distinta de aquella de que dispone para garantizar que los Estados miembros respeten los derechos fundamentales cuando aplican el Derecho de la Unión. Según jurisprudencia reiterada, los Estados miembros están obligados a respetar los derechos fundamentales en tanto que principios generales de Derecho comunitario. Pero dicha obligación sólo se extiende a las situaciones nacionales que corresponden al ámbito de aplicación del Derecho comunitario [3] Al contrario de lo que ocurre con los mecanismos que figuran en el artículo 7 TUE, el Tribunal de Justicia garantiza el respeto de dicha obligación como, por ejemplo, en el marco de un procedimiento por incumplimiento de una obligación (artículos 226 y 227 TCE) o de un recurso prejudicial (artículo 234 TCE). (Comisión Europea, 2003)

El artículo 7, apartado 1, del TUE solo se puede activar en caso de un «riesgo claro de violación grave» y el mecanismo sancionador del artículo 7, apartado 2, del TUE solo en caso de una «violación grave y persistente por parte de un Estado miembro» de los valores estipulados en el artículo 2. (Pérez, 2016)

De acuerdo con lo anterior, se presentan mecanismos preventivos y sancionadores, entre los cuales el primero permite al Consejo remitir un aviso a la UE y el segundo permite al Consejo suspender de manera temporal o definitiva la aplicación de los Tratados.

No obstante, estos mecanismos, como venimos reiterando, recientes acontecimientos en algunos Estados miembros han puesto de manifiesto como los mismos no son eficaces ni sirven para responder rápidamente a las amenazas al Estado de Derecho, por los que urge crear un nuevo marco europeo para reforzar el Estado de Derecho.

\section{Nuevo marco europeo para reforzar el estado de derecho}

En 2014 la Comisión Europea adoptó una Comunicación (CE, 2014) para reforzar el Estado de Derecho. Este nuevo marco propuesto pretende ser un complemento, un tertium genus, entre los procedimientos anteriormente descritos, a los que no suplanta, sino que complementa como una solución intermedia, que los precede y complementa respectivamente.

El objetivo del Marco es permitir a la Comisión Europea entablar un diálogo con el Estado miembro afectado con el fin de encontrar soluciones antes de recurrir a los mecanismos jurídicos existentes establecidos en el artículo 7 del Tratado y encontrar una solución, con el fin de prevenir la aparición de una amenaza sistémica para el Estado de Derecho, que afecte de forma negativa a la integridad, la estabilidad y el buen funcionamiento de las instituciones y mecanismos establecidos nacionalmente para garantizar el Estado de Derecho. El marco de la UE no está pensado para hacer frente a situaciones individuales o casos aislados de violación de los derechos fundamentales o errores judiciales. 
En principio, las «garantías del Estado de Derecho» nacionales deberían ser suficientes para abordar los posibles problemas y pueden hallarse en cada país en:

* el ordenamiento político, institucional o jurídico;

* su estructura constitucional;

* la separación de poderes (por ejemplo, entre el legislativo, el ejecutivo y el judicial);

* la independencia e imparcialidad de su poder judicial o su sistema de control judicial (es decir, cuando los tribunales pueden pronunciarse sobre la validez de una actuación).

De acuerdo con ello, el Marco se activa al momento en el cual las «garantías del Estado de Derecho» nacionales no puedan responder eficazmente a las diferentes amenazas en un país de la UE.

El proceso se divide en tres etapas:

a) Evaluación de la Comisión: La Comisión debe recopilar y analizar toda la información pertinente y valorar si hay indicios claros de una grave amenaza contra el Estado de Derecho. Si, como consecuencia de ello, la Comisión cree que, en efecto, existe una situación de amenaza sistémica contra el Estado de Derecho, entablará un diálogo con el Estado miembro afectado remitiéndole un «dictamen de Estado de Derecho», que será un aviso al Estado miembro, y justificando sus preocupaciones. Se dará al Estado miembro correspondiente la posibilidad de responder.

b) Recomendación de la Comisión: En una segunda etapa, la Comisión publicará una «recomendación del Estado de Derecho» dirigida al Estado miembro, a menos que el asunto ya ha sido resuelto de manera satisfactoria. Recomendará que el Estado miembro solucione los problemas detectados en un plazo fijo y que informe a la Comisión de las medidas adoptadas a tal efecto. La Comisión hará pública su recomendación.

c) Seguimiento de la Recomendación de la Comisión: En una tercera etapa, la Comisión supervisará el curso dado por el Estado miembro a la recomendación. Si ese curso no es satisfactorio en el plazo fijado, la Comisión podrá recurrir a uno de los mecanismos establecidos en el artículo 7 del TUE.

Todo el proceso se basa en un diálogo permanente entre la Comisión y el Estado miembro interesado. La Comisión mantendrá al Parlamento Europeo y al Consejo periódica y debidamente informados.

El Parlamento europeo, por su parte, se muestra muy crítico con la situación en la que se encuentra la Unión europea, y asumiendo el mismo punto de partida de la Comisión, señala que: 
La Unión tiene un gran número de instrumentos y procedimientos para garantizar la plena y correcta aplicación de los principios y los valores de los Tratados, pero que, en la prácti$\mathrm{ca}$, dichos instrumentos y procedimientos parecen tener un alcance limitado o resultar inadecuados e ineficaces, o es poco probable que sean usados; que son muchos los que consideran que su aplicación desigual se debe a motivos políticos, es arbitraria y se dirige injustamente a determinados Estados (Parlamento Europeo, 2016, p.6-7)

Ante esta realidad, y el hecho que algunos Estados nieguen que el respeto de los principios y valores de la Unión sean una obligación derivada de los Tratados o que la Unión tenga poder para obligar a su cumplimiento, da un paso más y propone, y sobre la base del art. 295 TFUE $^{8}$, la elaboración de un Pacto de la Unión sobre la Democracia, el Estado de Derecho y los Derechos Fundamentales, que incluyan elementos preventivos y correctores, y se apliquen a todos los Estados miembros, así como a las tres instituciones fundamentales de la Unión.

La Comisión acogió con satisfacción el objetivo general de la Resolución, que consiste en garantizar que los valores comunes de la UE se apliquen y se respeten 41. La Comisión considera, no obstante, que es preciso hacer el mejor uso posible de los instrumentos existentes, evitando los solapamientos. Una serie de agentes e instrumentos existentes ya aporta un conjunto de medios complementarios y eficaces para promover y defender los valores comunes. La Comisión seguirá valorando y aprovechando esos medios. Una de las ideas subyacentes del Parlamento fue hacer que los diferentes datos e informes existentes sobre la situación de los derechos fundamentales en los Estados miembros sean más accesibles y visibles, también en el ámbito nacional. La Comisión acogió con satisfacción esta idea, ya que otros muchos agentes -incluidos el Consejo de Europa y su Comisión de Venecia, la Agencia de los Derechos Fundamentales de la UE (FRA) y las ONG- recogen información sobre el Estado de Derecho, la democracia y los derechos fundamentales en los Estados miembros (CE, 2017)

\section{Conclusión: Avances y retrocesos.}

La Unión europea se encuentra en una encrucijada. Podría suponerse que el respeto a los derechos fundamentales, la democracia y el Estado de Derecho es algo obvio en un ámbito de integración regional como el nuestro, pero la realidad evidencia que no hay que darlo por sentado.

Como señala el Informe 2016 sobre la situación de los derechos fundamentales en la Unión,

La UE se enfrentó a múltiples retos: las consecuencias de la llegada sin precedentes de refugiados a sus fronteras exteriores, los desequilibrios económicos y una serie de atentados terroristas. Las personas que sufren las consecuencias de las múltiples crisis no confían en

${ }^{8}$ El Parlamento Europeo, el Consejo y la Comisión llevarán a cabo consultas recíprocas y organizarán de común acuerdo la forma de su cooperación. A tal efecto y dentro del respeto de los Tratados, podrán celebrar acuerdos interinstitucionales que podrán tener carácter vinculante. 
que sus hijos vayan a estar mejor que ellos mismos. Cuestionan si las instituciones son todavía capaces de protegerles de los retos y las amenazas de la migración, las turbulencias financieras y el terrorismo. En este contexto, el nacionalismo, el populismo y la intolerancia encuentran un terreno fértil para prosperar y defender la exclusión y el aislacionismo como la única manera de superar los retos actuales. (Parlamento Europeo, 2016)

Por otro lado, la globalización obliga a la Unión a replantearse su posición en un contexto global cada vez más complejo y cambiante, ante el surgimiento de nuevas potencias y el desplazamiento del poder económico-político hacia antiguas periferias. Pero como señala el Nobel Stiglitz, debe también preocuparnos que la globalización está produciendo países ricos con población pobre. Europa lo sabe bien tras la terrible crisis financiera que hemos sufrido y de la que aún nos lamemos las heridas.

Las relaciones internacionales, la lucha por posicionarse en los mercados mundiales no nos debe hacer olvidar el sagrado respeto a la democracia y los derechos humanos en todas partes del planeta. No se entendería que estemos luchando por consolidar el Estado de Derecho en nuestras fronteras, y mirásemos para otro lado en otras partes del planeta.

De esa forma la Unión tiene que seguir avanzando y consolidando el Estado de Derecho, reforzando los mecanismos de cooperación y control de los Estados miembros, para que aquella manida cláusula de "asuntos internos" no sirva para justificar agresiones graves a la democracia y los derechos fundamentales, ejes del Estado de Derecho.

No obstante, con ocasión de la crisis del denominado Covid19, se han constatado, en fecha reciente, esas discrepancias, esos retrocesos, y también algunos avances.

No obstante, esta propuesta, se ha producido un bochornoso espectáculo protagonizado dentro de la Unión Europea, de enfrentamiento de unos países contra otros, respecto a la dotación de fondos para luchar contra la pandemia y el futuro plan de reconstrucción, denominado informalmente como Plan Marshall 2, ante la más que cierta crisis económica y social que nos asolará, y cuyos efectos son todavía no cuantificables.

Todo comenzó por la cuestión relativa a la emisión o no de los llamados "coronabonos"; es decir, acudir a los mercados con el respaldo de la Unión Europea. Este era el gran debate acerca de la respuesta que debe dar Europa a la crisis económica que está por llegar tras la paralización de varias economías de la Zona Euro por el coronavirus.

Las posturas estaban muy enfrentadas, pese a que nueve países apoyaban los coronabonos y otros cinco no lo verían mal. En total, 14 países de los que componen la UE estarían a favor, pero en contra están algunos de los países más relevantes: Alemania, Finlandia, Holanda o Austria.

Esa postura de los países del norte fue poco a poco cambiando ante las presiones internas que sufrieron los Gobiernos de Holanda y Alemania, a los que se advirtió de 
que si se dejaba caer a países como Italia o España se podría producir una crisis como la de 2008, con el riesgo de que arrastrara al norte de Europa.

Posteriormente, tras numerosas conversaciones, y las correspondientes presiones diplomáticas, los Veintisiete lograron este jueves aprobar por fin un paquete de emergencia de más de medio billón de euros para luchar contra la pandemia después de que España e Italia lograran que el acceso a esos fondos no esté condicionado a ningún programa de ajustes o reformas, como querían los Países Bajos. Los titulares de Finanzas de la UE pactaron también crear un fondo para la recuperación económica que deberán abordar los jefes de Estado y de gobierno en la próxima cumbre.

El paquete pretende ser una triple red de seguridad: para gobiernos, empresas y trabajadores. El fondo de rescate europeo (Mede) será finalmente el salvavidas para los gobiernos que requieran de fondos en caso de un deterioro rápido de sus finanzas públicas. El acuerdo activa hasta $\mathbf{2 4 0 . 0 0 0 ~ m i l l o n e s ~ d e ~ e u r o s ~ q u e ~ p u e d e n ~ s o l i c i t a r ~ t o d o s ~}$ los países de la zona euro. A cambio, los países que pidan esos créditos se comprometen a estar dentro de las reglas fiscales de la UE, lo que incluye sus márgenes de flexibilidad (El País, 2020)

Este episodio que bien fue calificado como bochornoso, al menos, en sus inicios, se ha visto, sin embargo, justipreciado por lo estipulado por los mismos estados de la UE, estableciendo que la Comisión Europea debe elaborar un régimen de condicionalidad que incluya la observancia de los principios constitucionales, como el Estado de derecho, para recibir ayudas de la UE. En caso de violaciones del Estado de derecho se retendrán las ayudas para la pospandemia. Esta respuesta fue el resultado triunfalista a las manifestaciones de los presidentes de Hungría y Polonia, siempre los mismos, que tras la aprobación del Fondo de Recuperación pospandemia, a finales de julio de 2020, salieron exultantes anunciando su victoria en la Cumbre Extraordinaria europea al no vincular la garantía del Estado de derecho al cobro de ayudas. La realidad, afortunadamente, ha sido la contraria. (DW, 2020)

La situación real es, como han señalado recientemente, los dirigentes de los Estados miembros y de las instituciones europeas, que:

La Unión Europea se enfrenta a retos sin precedentes, tanto mundiales como interiores: conflictos regionales, terrorismo, presiones migratorias crecientes, proteccionismo y desigualdades sociales y económicas. Juntos estamos decididos a hacer frente a los retos de un mundo en rápida mutación y a brindar a nuestros ciudadanos tanto seguridad como nuevas oportunidades. Vamos a hacer a la Unión Europea más fuerte y resiliente, mediante una unidad y una solidaridad aún mayores entre nosotros y el respeto de las normas comunes. La unidad es una necesidad y nuestra libre elección. A nuestros países, tomados uno a uno, la dinámica mundial los condenaría a la marginación; permanecer unidos es nuestra mejor posibilidad de influir en ella y de defender nuestros intereses y valores comunes (Comisión Europea, 2017) 


\section{Referencias bibliográficas}

Comisión Europea, (2003), Comunicación de la comisión al consejo y al parlamento europeo sobre el artículo 7 del tratado de la unión europea - Respeto y promoción de los valores en los que está basada la Unión, https://eur-lex.europa.eu/legal-content/ES/TXT/PDF/?uri=CELEX:52003DC0606\&from=ES

Comisión Europea, (2014), Comunicación de la comisión al parlamento europeo y al consejo. Un nuevo marco de la UE para reforzar el Estado de Derecho. https://eur-lex.europa.eu/ resource.html?uri=cellar:caa88841-aa1e-11e3-86f9-01aa75ed71a1.0005.01/DOC_1\&forma$\mathrm{t}=\mathrm{PDF}$

Comisión Europea, (2014), Anexos de la comunicación de la comisión al parlamento europeo y del consejo. Un nuevo marco de la UE para reforzar el Estado de Derecho. https://data. consilium.europa.eu/doc/document/ST-7632-2014-ADD-1/es/pdf

Comisión Europea, (2016), Informe de la comisión al parlamento europeo, al consejo, al comité económico y social europeo y al comité de las regiones Informe de 2015 sobre la aplicación de la Carta de los Derechos Fundamentales de la UE, https://eur-lex.europa.eu/legal-content/ES/TXT/?uri=CELEX\%3A52016DC0265

Comisión Europea, (2017), Comunicación de la comisión al parlamento europeo, al consejo, al comité económico y social europeo y al comité de las regiones. Informe de 2016 sobre la aplicación de la Carta de los Derechos Fundamentales de la Unión Europea, https://eur-lex. europa.eu/legal-content/ES/ALL/?uri=CELEX\%3A52017DC0239

Comisión Europea, (2017), Documento de reflexión sobre el enacauzamiento de la globalización. https://eur-lex.europa.eu/legal-content/ES/TXT/PDF/?uri=CELEX:52017DC0240\&from=PL

Comité Económico y Social Europeo, (2016). Dictamen del Comité Económico y Social Europeo sobre «El mecanismo europeo de control del Estado de Derecho y los derechos fundamentales». https://eur-lex.europa.eu/legal-content/ES/TXT/PDF/?uri=CELEX:52016IE1275\&from=ET

Comité Económico y Social Europeo, (2019). Comunicación de la comisión al parlamento europeo y al consejo. Reforzar en mayor medida el Estado de Derecho en la Unión. Situación y posibles próximas etapas. https://www.ccoo.es/e1de34f842fbc4783e4164086afa9d5d000001.pdf

Parlamento Europeo, (2016), Proyecto de informe con recomendaciones destinadas a la Comisión sobre el establecimiento de un mecanismo de la Unión para la democracia, el Estado de Derecho y los derechos fundamentales, https://oeil.secure.europarl.europa.eu/oeil/ popups/ficheprocedure.do?lang=fr\&reference $=2015 / 2254($ INL)

Pellicer, L, (2020, abril 10). La UE acuerda desbloquear las ayudas de medio billón de euros contra la crisis del coronavirus. El País. https://elpais.com/economia/2020-04-09/la-ueacuerda-desbloquear-las-ayudas-de-medio-billon-de-euros-contra-la-crisis-del-coronavirus.html

Perez, Bernardez, C. (2016), "La Unión Europea frente a la erosión del Estado de Derecho: las respuestas jurídico-políticas al caso polaco”, Revista General de Derecho Europeo, 40, 49-94.

Pérez Luño, A, (2003), Derechos Humanos, Estado de Derecho y Constitución, Madrid, Tecnos. 
Riegert, B, (2020, septiembre 23), La UE condiciona ayudas pospandemia al respeto del Estado de derecho. $D W$. https://www.dw.com/es/la-ue-condiciona-ayudas-pospandemia-al-respeto-del-estado-de-derecho/a-54270629

Sánchez, A. (2017), "Algunas reflexiones sobre la crisis de refugiados en Europa: de la solidaridad a los muros", Refugiados e Migrações no século XXI: direitos fundamentais e relações internacionais, Belo Horizonte-MG, Arraes Editores.

Tribunal de Justicia de la Unión Europea (Sala Tercera), (1981). Asuntos acumulados 212 a 217/80 Amministrazione delle finanze dello Stato contra Salumi, https://eur-lex.europa.eu/legal-content/ES/TXT/?uri=CELEX\%3A61980CJ0212\&qid=1604460015159

Tribunal de Justicia de la Unión Europea, (1989), Asuntos acumulados 46/87 y 227/88, Hoechst contra Comisión, https://eur-lex.europa.eu/legal-content/ES/TXT/?uri=CELEX\%3A61987CJ0046

Tribunal de Justicia de la Unión Europea (Sala Sexta), (2004), Asunto C-496/99 P, Comisión contra CAS Succhi di Frutta Rec. 2004, I-03801, https://eur-lex.europa.eu/legal-content/ES/ TXT/?uri=CELEX\%3A61999CJ0496

Tribunal de Justicia de la Unión Europea (sala segunda), (2010), Asunto C-279/09 DEB, https://eur-lex.europa.eu/legal-content/ES/ TXT/?uri=CELEX\%3A62009CA0279\&qid=1604460997430

Tribunal de Justicia de la Unión Europea (gran sala), (2010), Asunto C-550/07 P Akzo Nobel Chemicals y AkcrosChemicals contra Comisión, https://eur-lex.europa.eu/legal-content/ES/ TXT/?uri=CELEX\%3A62007CJ0550

Tribunal de Justicia de la Unión Europea (gran sala), (2013). Asunto C-583/11 P Inuit TapiriitKanatami y Otros contra Parlamento y Consejo, https://eur-lex.europa.eu/legal-content/ES/ TXT/?uri=CELEX\%3A62011CJ0583

Unión Europea, (2010), Versión consolidada del tratado de la unión europea. https://eur-lex. europa.eu/LexUriServ/LexUriServ.do?uri=OJ:C:2010:083:FULL:ES:PDF

Unión Europea, (2016), Recomendación (UE) 2016/1374 de la Comisión, de 27 de julio de 2016, relativa al Estado de Derecho en Polonia. https://eur-lex.europa.eu/legal-content/ES/TXT/ PDF/?uri=CELEX:32016H1374\&from=IT

Unión Europea, (2016), Informe anual de la unión europea sobre los derechos humanos y la democracia en el mundo en 2015, https://www.consilium.europa.eu/media/29701/ qc0216616esn.pdf

Unión Europea, (2016), Recomendación (UE) 2017/146 de la Comisión, de 21 de diciembre de 2016, sobre el Estado de Derecho en Polonia que complementa la Recomendación (UE) 2016/1374. https://eur-lex.europa.eu/legal-content/ES/TXT/PDF/?uri=CELEX:32017H0146\&from=ES 